\title{
Carbohydrate Metabolism and Possible Mechanisms of Leaf Blackening in Protea neriifolia under Dark Postharvest Conditions
}

\author{
Robyn McConchie ${ }^{1}$ and N. Suzanne Lang ${ }^{2}$ \\ Department of Horticulture, Julian C. Miller Hall, Louisiana Agricultural Experiment Station, Louisiana \\ State University Agricultural Center, Baton Rouge, LA 70803 \\ Additional index words. antioxidants, glutathione, lipid peroxidation, source-sink, cut flowers
}

\begin{abstract}
During a 7-day dark postharvest period, Protea neriifolia R.Br. leaf blackening was significantly reduced on floral stems treated with a $24-\mathrm{h} 20 \%$ sucrose pulse compared with continuous holding in a $0.5 \%$ sucrose vase solution or removal of the flowerhead. Leaf blackening on vegetative stems was similar to that on the $20 \%$ sucrose-pulsed floral stems. Leaf starch and sucrose concentration profiles demonstrated that stems with reduced leaf blackening maintained higher levels of those carbohydrates during the early postharvest period. Conversely, leaf starch and sucrose reserves were quickly depleted in stem treatments that resulted in early blackening symptoms. Starch concentrations in all treatments of stems dropped $70 \%$ to $82 \%$ within $24 \mathrm{~h}$ of harvest, suggesting that leaf blackening may be initiated during shipping. Ethylene production was not associated with leaf blackening in any treatment. Lipid peroxidation did not differ among floral treatments nor did it increase over the postharvest interval. Oxidized glutathione (GSSG) concentration increased only with the $20 \%$ pulsed stems and was not related to leaf blackening. After an initial decrease, leaf respiration rate was generally maintained regardless of treatment. Collectively, these data are consistent with the hypothesis that carbohydrate depletion is the initiating factor in leaf blackening and is accelerated by inflorescence sink demand. We suggest that membrane degradation does not necessarily precede leaf blackening.
\end{abstract}

A major postharvest problem of many cut flower Protea species is premature leaf blackening. Blackening symptoms in susceptible species can appear within 3 to 7 days after harvest, severely reducing market quality. The onset of leaf blackening has been associated with diminished carbohydrate concentrations in leaves during the postharvest period (Bieleski et al., 1992; McConchie et al., 1991). Leaf blackening can be delayed in cut stems of $P$. neriifolia by placing them in light (McConchie et al., 1991; Reid et al., 1989), due to the contribution of leaf photosynthetic activity to the carbohydrate pool (McConchie et al., 1991). After harvest, nonstructural carbohydrates appear to be mobilized from leaves to the floral sink for continuation of floral development. Postharvest leaf carbohydrate profiles under light show that during periods of rapid floral expansion, fixed $\mathrm{C}$ is preferentially partitioned into transport carbohydrates. In contrast, when the flower is fully expanded or senescing, photoassimilates are partitioned into starch and stored in the leaves. Leaf blackening in cut Protea stems has reportedly been reduced by placement in vase solutions containing $0.2 \%$ to $2 \%$ sucrose or by removal of the flowerhead (Brink and de Swardt, 1986; Paul1 et al., 1980; Reid et al., 1989). Collectively, these data suggest that when demand for stored or newly fixed carbohydrates is reduced, there is a corresponding reduction in leaf blackening.

Whitehead and de Swardt (1982) hypothesized that the visual symptoms associated with leaf blackening are caused by oxidation of polyphenols and leuco-anthocyanins by polyphenol oxidase

Received for publication 11 June 1992. Accepted for publication 28 Sept. 1992. Paper no. 92-28-6204 of the Journal Series, Louisiana Agr. Expt. Sta., Louisiana State Univ. Agricultural Center. We are grateful to G. McClure for valuable technical assistance, G. Lang and B. Oldroyd for their critical review of the manuscript, and J. and M. Nelson, Goleta, Calif., for donation of flowers. The cost of publishing this paper was defrayed in part by the payment of page charges. Under postal regulations, this paper therefore must be hereby marked advertisement solely to indicate this fact.

'Graduate Research Assistant.

${ }^{2}$ Assistant Professor.
(PPO; EC 1.10.3.2) and peroxidases (POD; EC 1.11.1.7). This hypothesis suggests that there is a breakdown of membrane structure during the postharvest interval, which in turn, releases PPO from chloroplasts and phenolic substrates from vacuoles, resulting in leaf blackening. The question then arises as to how depletion of leaf carbohydrates and membrane degradation are physiologically linked.

Ferreira (1986) hypothesized that following carbohydrate depletion in Protea, cellular components may be hydrolyzed to supply respiratory substrate for the inflorescence. This seems unlikely since a pool of nonstructural carbohydrates remains in the leaves after the onset of leafblackening (Bieleski et al., 1992; McConchie et al., 1991). Our alternative hypothesis is that a metabolic imbalance, caused by depleted levels of carbohydrates, leads to oxidative stress responses and subsequent membrane damage. Production of toxic free radicals is a consequence of normal cell metabolism. However, their potentially toxic effect is usually mitigated by antioxidant or free radical-scavenging systems (Elstner, 1987; Winston, 1990). In a stressed cell, antioxidant effectiveness is often decreased, possibly resulting in free radical attack on lipids, proteins, and other macromolecules, leading to cellular disorganization and eventual death (Benson, 1990).

Glutathione is involved in a series of antioxidant reactions resulting in the detoxification of oxygen derivatives (Elstner, 1987; Larson, 1988). During darkness, the ascorbate-glutathione antioxidant system may have reduced efficacy due to diminishing availability of $\mathrm{NADPH}+\mathrm{H}^{+}$to regenerate reduced glutathione (GSH).

Loss of membrane integrity in stressed plants may also be brought about by free radical-mediated lipid peroxidation (Elstner, 1987; Winston, 1990). Free fatty acids, released from membranes via enzymatic catalysis or direct attack by free radicals during

Abbreviations: AER, assimilate export rate; CER, carbon exchange rate; DNMR, Duncan's new multiple range test; GSH, reduced glutathione; GSSG, oxidized glutathione; MDA, malionaldehyde; POD, peroxidases; PPO, polyphenol oxidase. 
stress, are subject to further attack by free radicals resulting in the formation of ethane and malionaldehyde. Presence of one or both of these compounds may be used to estimate the extent of lipid peroxidation in plant cells and, thus, indicate antioxidant status (Winston, 1990).

Ethylene is an important growth regulator often associated with stress responses and senescence in plant tissue and may induce accelerated cell death (Mattoo and Aharoni, 1988). In addition, ethylene may stimulate the activity of peroxidases (Gonzalez et al., 199 1). Therefore, the production of ethylene during the postharvest period by $P$. neriifolia leaves may help clarify some of the physiological mechanisms related to leaf blackening.

Here we report on preharvest leaf carbohydrate metabolism and postharvest leaf carbohydrate depletion to determine the influence of inflorescence sink demand during storage in darkness and to establish more clearly the timing and factors involved in the onset of leaf blackening. Ethylene production and the changes in two biological indicators of antioxidant status, glutathione, and lipid peroxidation, were measured to investigate the link between reduced carbohydrate concentration and possible mechanisms of membrane deterioration and leaf blackening.

\section{Materials and Methods}

Preharvest sampling. Based on uniformity of stem size and age, one vegetative and one floral stem were selected from three Protea neriifolia plants at a commercial plantation in Goleta, Calif., in Aug. 1991. Each stem was divided into seven phyllotactic divisions (one division equals one complete spiral of leaves, ca. 5 to 7 leaves) beginning at the distal end. Carbon exchange rate (CER) and stomatal conductance were measured at each division using a portable infrared gas analyzer (LI-COR model LI-6200, Lincoln, Neb.) at ambient photosynthetically active radiation (PAR) of $\approx 1975 \mu \mathrm{mol} \cdot \mathrm{m}^{-2} \cdot \mathrm{s}^{-1}$, as described by McConchie et al. (1991). Four leaf disks $(0.5 \mathrm{~cm}$ diameter $)$ were removed from each division at the beginning and end of $5 \mathrm{~h}$ of sampling for assimilate export rate (AER) estimation (Terry and Mortimer, 1972). Leaf disks were taken $2.5 \mathrm{~h}$ before and $2.5 \mathrm{~h}$ after CER and stomatal conductance measurements. Leaf disks were frozen and transported in liquid $\mathrm{N}_{2}$. Upon arrival in Baton Rouge, La., disks were lyophilized and weighed to provide an estimate of the rate of dry weight change per unit leaf area during the preharvest photoperiod. Weighed leaf disks were used for carbohydrate analysis as described for postharvest samples.

Postharvest sampling. Sixty-three floral (at soft tip maturity) and 21 vegetative stems were harvested from the same block at dawn the following day. Leaf samples were removed from the third and sixth phyllotactic division on three vegetative and nine floral stems, frozen in liquid $\mathrm{N}_{2}$, and stored at $-80 \mathrm{C}$ until required for enzyme and carbohydrate analysis. The remaining stems were packed under standard conditions for cut flowers and air-freighted to Baton Rouge, La. Stems were unpacked $24 \mathrm{~h}$ after harvest, and leaves were sampled from three vegetative and nine floral stems as described above. The remaining stems were re-cut $(1 \mathrm{~cm})$, placed in 1-liter deionized distilled $\mathrm{H}_{2} \mathrm{O}$ containing $50 \mathrm{ppm}$ hypochlorite (referred to as base solution), and assigned the following treatments: A) vegetative stem in base solution; B) floral stem, with flowerhead removed $24 \mathrm{~h}$ after harvest, in base solution; C) floral stem with $0.5 \%$ sucrose added to base solution; and D) floral stem with a 24-h $20 \%$ sucrose pulse followed by placement in base solution. All treatments were maintained in continuous darkness in a growth chamber (Environmental Growth Chambers, Chagrin Falls, Ohio) at $25 \mathrm{C}( \pm 1 \mathrm{C})$. Vase solutions were changed daily.
Each sample day, three stems were chosen randomly from each treatment for the same measurements. The number of leaves with $10 \%$ or more leaf area blackened was recorded and stomatal conductance (LI-COR Model LI-6200) measured on leaves from the third and sixth phyllotactic division. Leaves from those divisions were then removed from the stems and shredded and mixed to form a composite sample. Composite samples were weighed, frozen, and used for the glutathione and lipid peroxidation analyses. Samples were taken on days $0,1,3,4,5,6$, and 7 for all treatments. An additional sample was taken on day 2 for the $20 \%$ pulse treatment to observe effects of the pulse. All results for metabolic measurements (carbohydrate, respiration, ethylene, glutathione, and lipid peroxidation) are expressed as an average of the third and sixth phyllotactic divisions to better represent stem profiles during the postharvest interval.

Carbohydrate analysis. Four leaf disks $(0.5 \mathrm{~cm}$ diameter $)$ were removed from the third and sixth phyllotactic division for each treatment/sample day combination (total $=8$ disks/ treatment), frozen $(-80 \mathrm{C})$, and lyophilized. Leaf disks were ground in $3 \mathrm{ml}$ of $80 \%$ (v/v) ethanol using a Brinkman Polytron Homogenizer (Brinkman Instruments, Westbury, N.Y.). Soluble carbohydrates were extracted in a total of $9 \mathrm{ml} 80 \%$ (v/v) ethanol and evaporated to dryness according to the methods of Robbins and Pharr (1988). The samples were re-dissolved in $2 \mathrm{ml} 80 \%$ ethanol (v/v), and soluble carbohydrates per unit leaf area were determined using high performance liquid chromatography (HPLC) (Waters 501 HPLC Pump, Waters 410 Differential Refractive Index Detector, Milford, Mass.; Phenomenex Spherex $5 \mathrm{NH}_{2}$ Column, Torrance, Calif.) using $70 \%$ (v/v) acetonitrile. Sugars were identified and quantified based on retention times and area under the peak for the following standards (Sigma Chemical): 0.4\% 1,5-anhydro-Dglucitol (polygalatol), $0.1 \%$ fructose, $0.1 \%$ glucose, $0.2 \%$ sucrose, and $0.1 \%$ maltose.

The pellet remaining from ethanolic extraction was used for determination of starch concentration. Starch was hydrolysed by amyloglucosidase (EC 3.2.1.3) and concentrations determined enzymatically by detecting the released glucose (Robbins and Pharr, 1988).

Respiration, ethylene, glutathione, and lipid peroxidation analyses. For respiration determination, one leaf from each of the third and sixth phyllotactic division was removed, weighed, and placed in sealed 72-ml jars (two leaves/jar, three jars/treatment) fitted with a rubber septum in the lid. Carbon dioxide concentration in the head space was determined after $1 \mathrm{~h}$ in continuous darkness at $25 \mathrm{C}$, using gas chromatography (GC) (Varian, Model 3700, Walnut Creek, Calif.). The GC was equipped with a Porapak Q column and a flame ionization detector. The carrier gas was helium at a flow rate of $40 \mathrm{ml} \cdot \mathrm{min}^{-1}$.

A second set of leaf samples (two leaves/jar, three jars/treatment) was taken as described above for determination of ethylene evolution. Concentration in the head space was measured after $1 \mathrm{~h}$ under continuous darkness at $25 \mathrm{C}$, by means of a $\mathrm{GC}$ equipped with a flame ionization detector and an alumina column (80C) (Hewlett Packard, model 5790A, Avondale, Pa.). The carrier gas was helium at a flow rate of $20 \mathrm{ml} \cdot \mathrm{min}^{-1}$.

Total glutathione (GSH + GSSG) and oxidized glutathione (GSSG) concentrations were determined enzymatically from $0.5 \mathrm{~g}$ composite tissue from the third and sixth phyllotactic divisions, by the methods of Anderson (1985) and Dhindsa (1987) using the DTNB-GSSG reductase recycling assay. Sample preparation for GSSG followed the method of Smith (1985), with slight modification. A 1-ml aliquot of the supernatant obtained for total glutathione determination was neutralized with $1.5 \mathrm{ml}$ potassium 
phosphate buffer ( $\mathrm{pH}$ 7.5). Following addition of $50 \mu \mathrm{l}$ 2-vinyl pyridine, the emulsion was incubated for $1 \mathrm{~h}$ at $25 \mathrm{C}$. Total and oxidized glutathione were determined from a standard curve using known GSH and GSSG concentrations purchased from Sigma Chemical Co., St. Louis.

Malionaldehyde (MDA), a by-product of lipid peroxidation, was measured in $0.5 \mathrm{~g}$ composite tissue from the third and sixth phyllotactic divisions, using the thiobarbituric acid method described by Heath and Packer (1968).

Statistical analysis. The preharvest data sets were analyzed as factorial analyses of variance with two-way treatment structures (floral or vegetative stem, seven phyllotactic divisions, three replicate stems per stem-division combination). The postharvest data sets were analyzed as factorial analyses of variance with twoway treatment structures (four flower treatments, 7 days, three replicate stems per flower-day combination). Where appropriate, specific day-treatment combinations were examined using orthogonal contrasts. Individual day-treatment combinations were compared using Duncan's new multiple range test (DNMR) (Steel and Torrie, 1980). All data were analyzed using SAS (SAS Institute, Cary, N.C. 1987).

Although sampling and analysis from day 0 to day 7 followed a factorial experimental design, for graphical representation, floral samples before initiation of postharvest treatments were combined.

\section{Results}

Preharvest. Vegetative and floral stems did not differ statistically for CER $(P=0.33)$ or AER over all seven phyllotactic divisions $(P=0.54)$ (Fig. $1 \mathrm{~A}$ and $\mathrm{B})$. The pattern of CER was similar for floral and vegetative stems across all but the fourth phyllotactic division. Maximum $\mathrm{C}$ fixation occurred at divisions 4 to 6 , and 5 to 7 for floral and vegetative stems, respectively (Fig. 1A). AER was highly correlated with CER $(r=0.99, P<0.0001)$, suggesting that the majority of fixed $\mathrm{C}$ was exported in both floral and vegetative stems (Fig. 1B).
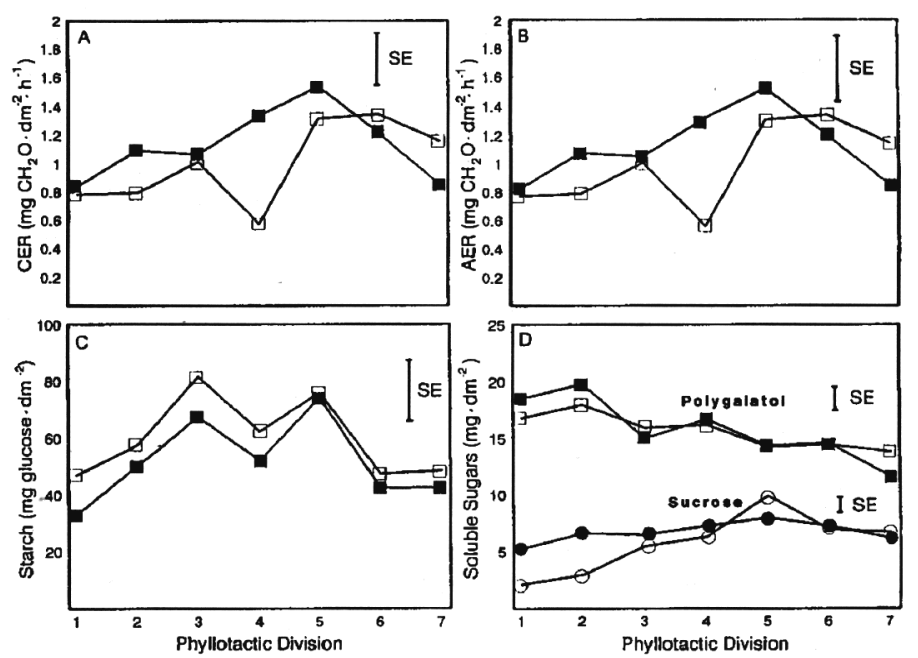

Fig. 1. Preharvest rates of photosynthesis and concentrations of nonstructural carbohydrates in leaves of field-grown Protea neriifolia stems in seven phyllotactic divisions (one division equals one complete spiral of leaves, ca. 5 to 7 leaves) from the distal end (Division 1) to the basal end (Division 7). Open symbols are vegetative stems. Closed symbols are floral stems. (A) $\mathrm{CER}\left(\mathrm{mg} \mathrm{CH} \mathrm{CH}_{2} \mathrm{O} / \mathrm{dm}^{2}\right.$ per h), (B) AER ( $\mathrm{mg} \mathrm{CH}_{2} \mathrm{O} / \mathrm{dm}^{2}$ per h), (C) starch concentration (mg glucose/ $\left.\mathrm{dm}^{2}\right),($ D $)$ soluble sugar concentration $\left(\mathrm{mg} \cdot \mathrm{dm}^{-2}\right)$. Bars indicate the maximum SE associated with least square means $(n=3)$.
Starch was the most abundant nonstructural carbohydrate in floral and vegetative stems; however, over all phyllotactic divisions, concentrations were not significantly different between stem type $(P=0.40)$ (Fig. 1C). Concentrations fluctuated across the seven divisions ranging from 32.7 to $88.3 \mathrm{mg}$ glucose $/ \mathrm{dm}^{2}$.

The major soluble sugars found in leaves were 1,5-anhydro-Dglucitol (polygalatol) and sucrose (Fig. 1D). Fructose, glucose, and maltose were found in concentrations of $<1.7 \mathrm{mg} \cdot \mathrm{dm}^{-2}$ and are not reported. Neither polygalatol nor sucrose concentrations differed significantly between floral and vegetative stems $(P=0.87$ and 0.14 , respectively); however, polygalatol concentrations were higher than sucrose concentrations in floral and vegetative stems across all divisions. Phyllotactic division significantly influenced concentrations of polygalatol $(P=0.0001)$ and sucrose $(P=0.003)$. Polygalatol concentrations were highest in the most acropetal divisions and decreased basipetally. In contrast, sucrose concentrations were lowest in the acropetal divisions and increased basipetally.

Postharvest treatments. Both, duration of postharvest holding (days) $(P=0.0001)$ and treatment $(P=0.006)$ were related to the amount of leaf blackening (Fig. 2A). Overall, the vegetative stems and floral stems pulsed with $20 \%$ sucrose had significantly less $(P$ c 0.05) leaf blackening than either those decapitated or kept in $0.5 \%$ sugar solution. In the decapitated stems and those in $0.5 \%$ sugar solution, the rate of leaf blackening increased rapidly after day 3 , reaching a maximum of $71 \%$ and $87 \%$, respectively, by day 7. In contrast, the rate of leaf blackening was lower for the vegetative and pulsed stems and did not exceed $27 \%$ for either treatment throughout the 7-day postharvest period.

Starch concentrations decreased dramatically (70\% to $82 \%$ ) within the first $24 \mathrm{~h}$ of harvest for all stems (Fig. 2B). Concentrations preharvest (day 0$)$ were significantly higher $(P=0.0001)$ than on all other days. Starch concentrations in leaves of vegetative stems declined more gradually than in those of floral stems;
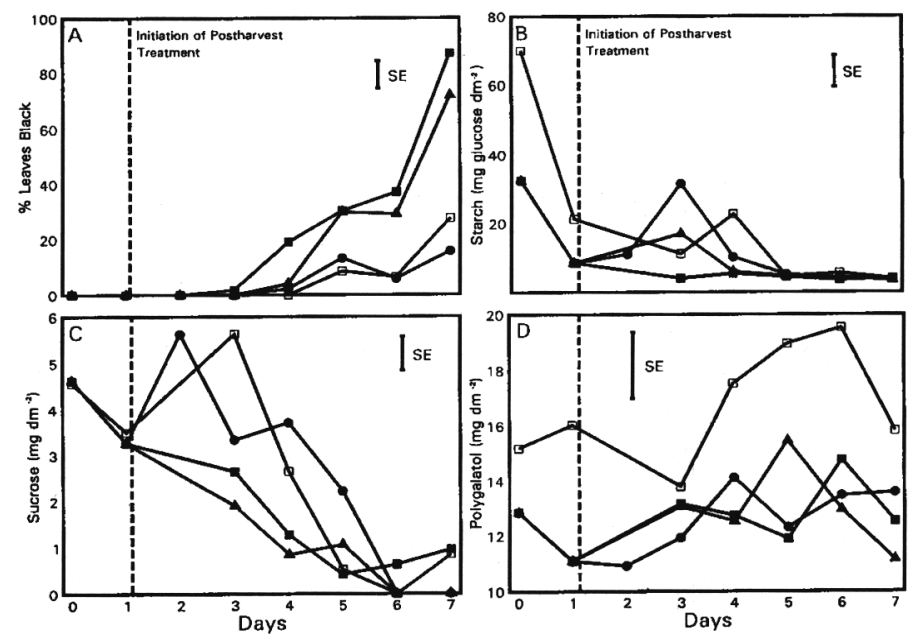

Fig. 2. Changes in postharvest leaf blackening and nonstructural carbohydrate concentrations in leaves of cut Protea neriifolia stems taken at harvest (Day 0), after a dark 24-h shipping period (Day 1), and each day thereafter while kept in $24 \mathrm{~h}$ darkness $(25 \mathrm{C} \pm 1 \mathrm{C})$ for 6 days. Treatments are: $(\square)$ vegetative stems, $(\boldsymbol{\Delta})$ floral stem with flowerhead removed $24 \mathrm{~h}$ after harvest, $(\square)$ floral stems with $0.5 \%$ sugar in vase solution, (O) floral stems placed in $20 \%$ sugar pulse, from 24 to $48 \mathrm{~h}$ after harvest. The treatments were applied immediately after the 24-h shipping period. (A) percent leaves with at least $10 \%$ blackened leaf area, (B) starch concentration, (C) sucrose concentration, (D) polygalatol concentration. The vertical line indicates the time at which stems were placed in their respective vase solutions and postharvest treatments were imposed. Bars indicate the maximum SE associated with least square means $(n=3)$. 
Table 1. Average Protea neriifolia leaf concentrations of total glutathione (GSH + GSSG) and oxidized glutathione (GSSG) at preharvest (Day 0), after a 24-h dark shipping period (Day 1), and each day thereafter for 6 days while kept in $24 \mathrm{~h}$ darkness $(25 \pm 1 \mathrm{C})$. Treatments assigned were vegetative stems, floral stems with flowerhead removed (decapitated), $0.5 \%$ sugar added to vase solution, or $24 \mathrm{~h} 20 \%$ sugar pulse.

\begin{tabular}{|c|c|c|c|c|}
\hline \multirow[b]{2}{*}{ Day } & \multicolumn{4}{|c|}{ Total glutathione (GSH + GSSG) (nmols $\cdot \mathrm{g}^{-1}$ fresh wt). } \\
\hline & Vegetative & Decapitated & $0.5 \%$ Sugar & $20 \%$ Pulse \\
\hline \multicolumn{5}{|c|}{ Pretreatment } \\
\hline 0 & $2.81^{z}$ & 3.39 & 5.46 & 2.66 \\
\hline 1 & 2.10 & 2.84 & 2.98 & 3.17 \\
\hline \multicolumn{5}{|c|}{ Initiation of postharvest treatment } \\
\hline 2 & --- & --- & --- & 3.08 \\
\hline 3 & 3.75 & 3.76 & 2.55 & 3.75 \\
\hline 4 & 2.83 & 2.37 & 3.03 & 3.40 \\
\hline 5 & 4.00 & 5.28 & 3.26 & 5.96 \\
\hline 6 & 3.67 & 5.37 & 2.92 & 5.84 \\
\hline 7 & 2.80 & 4.28 & 3.56 & 5.59 \\
\hline Trt mean & $3.45 \mathrm{~b}$ & $4.00 \mathrm{~b}$ & $3.03 \mathrm{~b}$ & $4.53 \mathrm{a}$ \\
\hline \multicolumn{5}{|c|}{ Oxidized glutathione (GSSG) (nmols $\cdot \mathrm{g}^{-1}$ fresh wt) } \\
\hline \multicolumn{5}{|c|}{ Pretreatment } \\
\hline 0 & $0.04^{y}$ & 0.00 & 0.23 & 0.00 \\
\hline 1 & 0.07 & 0.26 & 0.04 & 0.11 \\
\hline \multicolumn{5}{|c|}{ Initiation of postharvest treatment } \\
\hline 2 & --- & --- & --- & 0.15 \\
\hline 3 & 0.09 & 0.05 & 0.18 & 0.24 \\
\hline 4 & 0.00 & 0.03 & 0.06 & 0.66 \\
\hline 5 & 0.00 & 0.18 & 0.04 & 0.64 \\
\hline 6 & 0.06 & 0.31 & 0.44 & 0.77 \\
\hline 7 & 0.70 & 0.69 & 0.34 & 0.43 \\
\hline Trt mean & $0.13 b$ & $0.17 \mathrm{~b}$ & $0.19 \mathrm{~b}$ & $0.47 \mathrm{a}$ \\
\hline
\end{tabular}

${ }^{\mathrm{z}}$ Mean SE of the least square means is 1.10 .

${ }^{y}$ Maximum SE of the least square means is 0.28 .

Treatment means within rows followed by a different letter are significantly different at the $5 \%$ level (2-tailed $t$ test).

however, concentrations in all treatments had decreased by an average of $88 \%$ by day 5 . Starch concentrations in leaves of stems in $0.5 \%$ sugar solution, expressed as glucose, dropped to 4.2 $\mathrm{mg} \cdot \mathrm{dm}^{-2}$ within the first $24 \mathrm{~h}$ and remained low throughout the postharvest interval. In contrast, after an initial decline during shipping, starch concentrations in the pulsed stems increased significantly $(P<0.05) 48 \mathrm{~h}$ after initiation of the pulse treatment (day 3). Starch concentrations on day 3 for the pulse treatment were similar to concentrations measured preharvest and were significantly higher $(P=0.01)$ than in the decapitated stems or those in $0.5 \%$ sugar solution. However, by day 4 , starch concentrations in the pulsed flowers decreased to levels similar to other treatments.

There was no significant difference in sucrose concentrations among treatments $(P=0.20)$ (Fig. 2C); however, regressions of concentrations on day indicated a significant decline $(P<0.001)$ over the postharvest interval. In the decapitated stems and those in $0.5 \%$ sugar solution, sucrose concentrations decreased rapidly during the first 4 days after harvest and remained low. Over the same period, vegetative stems maintained higher sucrose concentrations, but then decreased to similar low levels on day 5. Sucrose concentrations in the pulsed stems significantly increased $(P=$ $0.0001) 24 \mathrm{~h}$ after the pulse, to $\approx 25 \%$ above their preharvest level. This increase preceded the increase in starch concentration (Fig. 2B) that occurred $48 \mathrm{~h}$ after the pulse treatment was initiated.

Polygalatol concentrations were significantly higher $(\mathrm{P}<0.05)$

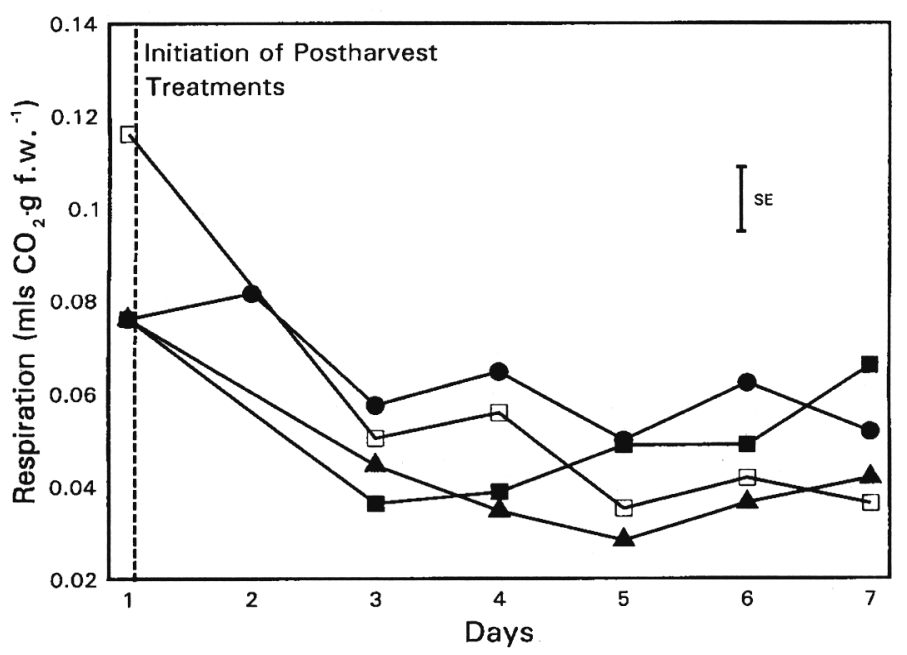

Fig. 3. Changes in postharvest respiration rate in leaves of cut Protea neriifolia stems taken after a dark 24-h shipping period (Day 1), and each day thereafter while kept in $24 \mathrm{~h}$ darkness $(25 \pm 1 \mathrm{C}$ ) for 6 days. Treatments are $(\square)$ vegetative stems, ( $\boldsymbol{\Delta}$ ) floral stem with flowerhead removed $24 \mathrm{~h}$ after harvest, ( $\square$ ) floral stems with $0.5 \%$ sugar in vase solution, (O) floral stems placed in $20 \%$ sugar pulse, from 24 to $48 \mathrm{~h}$ after harvest. Treatments were applied immediately after the 24-h shipping period. The vertical line indicates the time stems were placed in their respective vase solutions and postharvest treatments were imposed. Bars indicate the maximum SE associated with least square means $(n=3)$. 
in the vegetative stems than in floral stems of the other treatments throughout the postharvest period (Fig. 2D). In general, polygalatol concentrations for all treatments increased slightly or were generally maintained over the 7 days, in contrast to the sucrose concentrations, which declined dramatically.

Leaf respiration was significantly higher on day 1 for the vegetative stems, decapitated stems, and those in $0.5 \%$ sugar solution than on the other days $(P<0.05)$ (Fig. 3). However, after day 3 , respiration rate in these treatments was generally maintained for the remainder of the postharvest period. In the pulse stems, respiration increased on day 2 , before declining to a rate similar to that in other treatments.

No ethylene evolution $\left(<0.1 \mu \mathrm{l} \cdot\right.$ liter $\left.^{-1}\right)$ was detected from leaves in any treatment throughout the postharvest period (data not shown).

Stomatal conductance in the vegetative stems was significantly higher $(P<0.05)$ than in stems of other treatments; however, there was no significant difference between floral treatments (data not shown). Stomatal conductance fluctuated between 0.16 and 0.40 $\mathrm{mol} \cdot \mathrm{m}^{-2} \cdot \mathrm{s}^{-1}$ for leaves of all floral treatments, while conductance in those of vegetative stems ranged between 0.25 to $0.45 \mathrm{~mol} \cdot \mathrm{m}^{-2} \cdot \mathrm{s}^{-1}$. Stomata1 conductance measured postharvest was within the same range as that measured preharvest $\left(0.10\right.$ to $\left.0.45 \mathrm{~mol} \cdot \mathrm{m}^{-2} \cdot \mathrm{s}^{-1}\right)$.

Overall, total glutathione (GSH + GSSG) concentration did not differ significantly among treatments $(P=0.03)$; however concentration over days did not differ significantly $(P=0.06)$ (Table 1$)$. Concentrations of total glutathione in leaves of the pulsed stems were higher than the other treatments $(P<0.05)$. Additionally, total glutathione in leaves of the pulsed and decapitated stems increased at day 5, while variations in total glutathione for other treatments did not exhibit any consistent trends.

Both, duration of postharvest holding (days) $(P=0.04)$ and treatment $(P=0.03)$ significantly influenced GSSG concentrations (Table 1). The $20 \%$ pulse treatment led to increased concentrations of GSSG over the postharvest period and they were significantly higher overall than those in other treatments $(P=$ 0.006). In contrast, GSSG in vegetative stems remained low until day 6 , but was on average, not significantly different from that in the decapitated stems or those in $0.5 \%$ sugar solution $(P=0.08)$.
In general, GSSG concentrations in these two treatments remained relatively low until day 5, after which, concentrations rose to levels similar to those of the pulsed stems.

Lipid peroxidation in vegetative stems, as determined by malionaldehyde concentration, was significantly less than in stems of the other treatments $(P<0.05)$ (Table 2$)$. The rate of lipid peroxidation did not change significantly $(P=0.10)$ over the postharvest interval for either the stems that remained green (pulsed and vegetative stems) or the stems that had higher incidence of leaf blackening (those decapitated or in $0.5 \%$ sugar solution).

\section{Discussion}

The CER measured preharvest on intact $P$. neriifolia plants (Fig. 1A) was similar to that measured on cut floral stems in our previous work under low light intensities $\left(120 \mu \mathrm{mol} \cdot \mathrm{m}^{-2} \cdot \mathrm{s}^{-1}\right)$ (McConchie et al., 1991). In both cases, CER appears to be low in comparison with that of other woody species (Flore and Lakso, 1990). In addition, AER (Fig. 1B) follows the same pattern as CER in floral and vegetative stems. The similarity of CER and AER of floral and vegetative stems on intact plants is unexpected. Pharr et al. (1985) have shown that presence of a strong sink, such as that imposed by flowers or developing fruits, may result in accelerated leaf $\mathrm{C}$ exchange rates compared with vegetative plants. Our data demonstrate that presence of a floral sink does not result in increased CER or AER compared to vegetative stems. In addition, the similarity of carbohydrate profiles between floral and vegetative stems before harvest suggest that leafblackening in $P$. neriifolia may be related more to floral sink demand after harvest rather than to carbohydrate status before harvest.

Addition of exogenous sugar to the vase solution in concentrations of $0.2 \%$ to $2 \%$, or removal of the flowerhead are reportedly beneficial in delaying leaf blackening in Protea stems (Brink and de Swardt, 1986; Newman et al., 1989), while higher concentrations exacerbate blackening symptoms (Reid et al., 1989). Sensitivity to high sugar concentrations has been observed in leaves of other cut flowers, which Halevy (1976) suggests may be due to adverse osmotic effects of concentrated sugar uptake into leaf

Table 2. Average Protea neriifolia leaf malionaldehyde concentrations at preharvest (Day 0), after a 24-h dark shipping period (Day 1), and each day thereafter for 6 days while kept in 24 $\mathrm{h}$ darkness $(25 \pm 1 \mathrm{C})$. Treatments assigned were vegetative stems, floral stems with flowerhead removed (decapitated), $0.5 \%$ sugar added to the vase solution, or $24 \mathrm{~h} 20 \%$ sugar pulse.

\begin{tabular}{|c|c|c|c|c|}
\hline \multirow[b]{2}{*}{ Day } & \multicolumn{4}{|c|}{ Malionaldehyde concn $\left(\mathrm{nmol} \cdot \mathrm{g}^{-1}\right.$ fresh wt) } \\
\hline & Vegetative & Decapitated & $0.5 \%$ Sugar & $20 \%$ Pulse \\
\hline \multicolumn{5}{|c|}{ Pretreatment } \\
\hline 0 & $0.26^{2}$ & 0.34 & 0.33 & 0.42 \\
\hline 1 & 0.31 & 0.36 & 0.32 & 0.46 \\
\hline \multicolumn{5}{|c|}{ Initiation of postharvest treatment } \\
\hline 2 & --- & --- & --- & 0.37 \\
\hline 3 & 0.32 & 0.39 & 0.28 & 0.33 \\
\hline 4 & 0.23 & 0.37 & 0.34 & 0.37 \\
\hline 5 & 0.21 & 0.28 & 0.31 & 0.35 \\
\hline 6 & 0.19 & 0.30 & 0.39 & 0.30 \\
\hline 7 & 0.34 & 0.38 & 0.36 & 0.41 \\
\hline Trt mean & $0.26 \mathrm{~b}$ & $0.35 \mathrm{a}$ & $0.33 \mathrm{a}$ & $0.36 \mathrm{a}$ \\
\hline
\end{tabular}

${ }^{\mathrm{z}}$ Maximum SE of the least square means was 0.07 .

Means within rows followed by a different letter are significantly different at the 5\% level (2tailed $t$ test). 
cells. Our data indicate that floral stems are more predisposed to leaf blackening than vegetative stems after 3 days in darkness (Fig. 2A). In addition, removal of the flowerhead after the $24 \mathrm{~h}$ shipping period, or addition of $0.5 \%$ sugar to the vase solution, was of little benefit in delaying the appearance of leaf blackening symptoms. In contrast, our data indicate that treatment of floral stems with a $24 \mathrm{~h} 20 \%$ pulse significantly reduces leaf blackening. In $P$. cynaroides (L.) L., Jones (1991) reported reduced leaf blackening, relative to a water control, after a $20 \%$ pulse treatment during a 28 day storage period followed by a 9-day vase life. Pulsing of $P$. neriifolia resulted in reduced leaf blackening during the storage period, but inhibition was not maintained after storage. Jones (199 1) suggested that this treatment reduces leaf water loss during storage, thereby protecting membrane integrity. Leaves may therefore avoid adverse osmotic effects by rapid stomatal closure. However, our comparison of stomatal conductance measurements among all floral treatments indicate that the pulse treatment did not induce stomatal closure. We, therefore, suggest that limitation of the $20 \%$ sugar pulse to $24 \mathrm{~h}$ may account for the beneficial rather than deleterious effects previously observed when using high sucrose concentrations in the vase solution.

The carbohydrate profiles presented for each treatment substantially support the link between rate of leaf blackening and carbohydrate concentration (Fig. 2 A, B, and C). Vegetative stems had less leaf blackening, and up until day 4, maintained higher levels of starch and sucrose than decapitated stems and those in the $0.5 \%$ solution. Additionally, with the $20 \%$ sucrose pulse, starch, and sucrose concentrations increased on days 2 and 3 respectively, in response to supply of exogenous sugar, and they also had reduced leaf blackening relative to other floral stems. The rapid decline to low starch and sucrose concentrations and correspondingly high rate of leaf blackening in the decapitated stems and those in $0.5 \%$ sugar solution further supports the hypothesis that carbohydrate stress triggers leaf blackening. In all treatments, a substantial decrease in starch and sucrose concentrations preceded the appearance of blackening symptoms. Polygalatol is a major component of the soluble carbohydrate fraction in $P$. neriifolia, which, unlike starch and sucrose, did not decline over the postharvest period. Our data indicate that polygalatol does not contribute to the carbohydrate metabolic pool and that it is unavailable to the cut stem even under carbohydrate stress. Similar results were found in P. eximia (Salis. x Knight) Fourcade by Bieleski et al. (1992). They suggest that polygalatol may play a role in osmotic buffering of the cell in a dry habitat.

Of particular interest is the sharp drop in starch concentration for all treatments during the first $24 \mathrm{~h}$ (Fig. 2B). In our previous study (McConchie et al., 1991), floral stems placed in a vase solution containing $0.5 \%$ sugar under light developed leaf blackening on only $2 \%$ of the leaves. In contrast, $16.5 \%$ of leaves on floral stems without an exogenous sugar source developed blackening, despite placement under light. Based on our present data, we suggest that the large drop in leaf carbohydrate concentrations so soon after harvest initiates leaf blackening. Furthermore, removal of the flowerhead $24 \mathrm{~h}$ after harvest did not delay leaf blackening, even though the inflorescence sink no longer existed. The carbohydrate depletion that occurred immediately after harvest in this treatment, which was not reversed in darkness, possibly led to early leaf blackening. Starch concentrations also decreased during shipping of the pulsed stems; however, application of the 24-h 20\% sucrose pulse clearly resulted in a temporary increase in leaf carbohydrate concentration during a period of flower opening. After stems were placed in the pulse solution, leaf sucrose concentrations increased above that measured before harvest (Fig. 2C).
Starch concentrations in the pulsed stems showed a corresponding peak $24 \mathrm{~h}$ after completion of the pulse treatment (Fig. 2B). The data suggest that sucrose was taken up by the stem in excess of the sink demand and was subsequently partitioned into starch reserves. We, therefore, suggest that leaf blackening in floral stems may be induced during shipping and that it is irreversible unless stems are placed in light or are provided with sufficient carbohydrate substrate.

Whitehead and de Swardt (1982) suggested that leaf blackening symptoms are caused by oxidation of polyphenols and leucoanthocyanins, catalyzed by PPO and POD. PPO is a plastid enzyme (Vaughn and Duke, 1984), while phenols are sequestered in the vacuoles. Therefore, membrane disruption must occur to allow phenolic substrates and PPO to come in contact. We tested the hypothesis that oxidative stress, caused by the metabolic imbalance of depleted carbohydrates, leads to the membrane degradation that may result in oxidation of the phenols. Accordingly, we expected that concentrations of GSSG would increase in stems of treatments that developed greater leaf blackening in response to increased oxidative stress. Instead, GSSG only increased significantly in the pulsed stems, which had low levels of leaf blackening (Table 1 and Fig. 2A). Thus, our data suggest that the onset of leaf blackening did not involve increased antioxidant activity by the ascorbate-glutathione cycle. In addition to removal of free radicals, glutathione plays a major role in enzyme induction, sulphur metabolism, and gene expression (Alscher, 1989; Foyer et al., 1991; Rennenberg, 1982). Therefore, increased carbohydrate substrate provided by the pulse may have resulted in increased metabolic activity for maintenance and repair mechanisms, thereby placing increased reductive demands on glutathione.

Our data indicate that peroxidation of membranes as determined by malionaldehyde concentrations did not differ among floral treatments or increase over the 7-day postharvest period (Table 2); thus, membrane integrity did not appear to be reduced. Further, lipid peroxidation was not related to the extent of leaf blackening. Additional support for maintenance of membrane integrity is indicated by the respiration rate (Fig. 3), which was fairly constant after day 2, even though blackening was well advanced in the decapitated stems and those in $0.5 \%$ sugar solution at the end of the postharvest period. This result suggests that mitochondrial membranes remained intact during this time.

While our data are consistent with the hypothesis that inflorescence sink demand leads to substantial leaf starch and sucrose depletion within $24 \mathrm{~h}$ of harvest, and subsequent leaf blackening of $P$. neriifolia, the physiological mechanisms that permit oxidative enzymes and phenolic substrates to interact are yet to be resolved. Leaves of $P$. neriifolia contain the phenolic glycoside arbutin (Rheede van Oudtshoorn, 1963), which may be degraded when carbohydrates are depleted to release glucose and free phenolics. Peroxidases, which have been found in the vacuoles of some plant species (Boller, 1982; Cassab and Varner, 1988; Thomas and Jen, 1980) could be responsible for oxidation of the free phenolics, thus providing a possible mechanism for leaf blackening to occur.

\section{Literature Cited}

Alscher, R.G. 1989. Biosynthesis and antioxidant function of glutathione in plants. Physiologia Plant. 77:457-464.

Anderson, M.E. 1985. Determination of glutathione and glutathione disulfide in biological samples. Methods Enzymol. 13:548-555.

Benson, E.E. 1990. Free radicals in stresses and aging plant tissue cultures, p. 269-284. In: R. Rodriguez, R. Sanchez Tames, and D.J. Durzan. (eds.). Plant aging-basic and applied approaches. Ser. A: Life Sciences, vol. 186. Plenum Press, New York. 
Bieleski, R.L., J. Ripperda, J.P. Newman, and M.S. Reid. 1992. Carbohydrate changes and leaf blackening in cut flower stems of Protea eximia. J. Amer. Soc. Hort. Sci. 117:124-127.

Boller, T. 1982. Enzyme equipment of plant vacuoles. Physiol. Veg. 20:247-257.

Brink, J.A. and G.H. de Swardt. 1986. The effect-of sucrose in a vase solution on leaf browning of Protea neriifolia. Acta Hort. 185: 11 1-1 19.

Cassab, G.I. and J.E. Varner. 1988. Cell wall proteins. Annu. Rev. Plant Physiol. 39:321-353.

Dhindsa, R.S. 1987. Glutathione status and protein synthesis during drought and subsequent rehydration in Tortula ruralis. Plant Physiol. 83:816-819.

Elstner, E.F. 1987. Metabolism of activated oxygen species, p. 253-315 In: D.D. Davies. (ed.). The biochemistry of plants. vol. 11. Biochemistry of metabolism. Academic Press, Harcourt Brace Jovanovich, San Diego.

Ferreira, D.I. 1986. The influence of temperature on the respiration rate and browning of Protea neriifolia R. Br. inflorescences. Acta Hort. 185:121-129.

Foyer, C., M. Lelandais, C. Galap, and K.J. Kunert. 1991. Effects of elevated cytosolic glutathione reductase activity on the cellular glutathione pool and photosynthesis in leaves under normal and stress conditions. Plant Physiol. 97:863-872.

Flore, J.A. and A.N. Lakso. 1990. Environmental and physiological regulation of photosynthesis in fruit crops. Hort. Rev. 11: 111-157.

Gonzalez, A., R.S. Tames, and R. Rodriguez. 1991. Ethylene in relation to protein, peroxidase and polyphenol oxidase activities during rooting in hazelnut cotyledons. Physiologia Plant. 83:611-620.

Halevy, A.H. 1976. Treatments to improve water balance of cut flowers. Acta Hort. 64:223-230.

Heath, R.L. and L. Packer. 1968. Photoperoxidation in isolated chloroplasts. 1. Kinetics and stoichiometry of fatty acid peroxidation. Arch. Biochem. Biophys. 125:189-198.

Jones, R.B. 1991. Understanding and controlling leaf blackening in Protea leaves: The use of high concentrations of sucrose. Proc. Intl. Protea Assn., 6th Bienn. Conf. Perth, W.A. Australia. 22 to 27 Sept., p. 313-322.

Larson, Richard A. 1988. The antioxidants of higher plants. Rev. Article no. 30. Phytochemistry 27:969-978.

Mattoo, A.K. and N. Aharoni. 1988. Ethylene and plant senescence, p. 241-280. In: L.D. Nooden and A.C. Leopold. (eds.) Senescing and aging in plants. Academic Press, San Diego.

McConchie, R., N.S. Lang, and K.C. Gross. 1991. Carbohydrate depletion and leaf blackening in Protea neriifolia. J. Amer. Soc. Hort. Sci. 116:1019-1024.

Newman, J.P., W. van Doorn, and M.S. Reid. 1989. Carbohydrate stress causes leaf blackening. J. Intl. Protea Assn. 18:44-46.

Paull, R., R.A. Criley, P.E. Parvin, and T. Goo. 1980. Leaf blackening in Protea eximia; importance of water relations. Acta Hort. 113:159-166.

Pharr, D.M., S.C. Huber, and H.N. Sox. 1985. Leaf carbohydrate status and enzymes of translocate synthesis in fruiting and vegetative plants of Cucumis sativus L. Plant Physiol. 77:104-108.

Reid, M.S., W. van Doom, and J.P. Newman. 1989. Leaf blackening in Proteas. Acta Hort. 261:81-84.

Rennenberg, H. 1982. Glutathione metabolism and possible biological roles in higher plants. Phytochemistry 21:2771-2781.

Rheede van Oudtshoorn, M.C.B. van. 1963. Distribution of phenolic compounds in some South African Proteaceae. A contribution to the chemotaxonomy of the family. Planta Medica 4:399-406.

Robbins, N.S. and D.M. Pharr. 1988. Effect of restricted root growth on carbohydrate metabolism and whole plant growth of Cucumis sativus L. Plant Physiol. 87:409-413.

SAS Institute, 1987. SAS/STAT Guide for Personal Computers. version 6 ed. SAS Institute, Cary N.C.

Smith, I.K. 1985. Stimulation of glutathione synthesis in photorespiring plants by catalase inhibitors. Plant Physiol. 79:1044-1047.

Steel, R.G.D. and J.H. Torrie. 1980. Principles and procedures of statistics. A biometrical approach. 2nd ed. p. 18 1. McGraw-Hill Kogakusha, New York.

Terry, N. and D.C. Mortimer. 1972. Estimate of the rates of mass carbon transfer by leaves of sugar beet. Can. J. Bot. 50: 1049-1054.

Thomas, R.L. and J.J. Jen. 1980. The cytochemical localization of peroxidase in tomato fruit cells. J. Food Biochem. 4:247-259.

Vaughn, K.C. and S.O. Duke. 1984. Function of polyphenol oxidase in higher plants. Physiologia Plant. 60: 106-1 12.

Whitehead, C.S. and G.H. de Swardt. 1982. Extraction and activity of polyphenoloxidase and peroxidase from senescing leaves of Protea neriifolia. Sth. African J. Bot. 1:127-130.

Winston, G.W. 1990. Physiochemical basis for free radical formation in cells: Production and defenses. p. 57-86. In: R.G. Alscher and J.R. Cumming (eds.). Stress responses in plants: Adaptation and acclimation mechanisms. Plant Biol. vol. 12. Wiley-Liss, New York. 